\title{
A Multi-period Model for Managing Used Product Returns
}

\author{
George Nenes ${ }^{\mathrm{a}}$, Yiannis Nikolaidis ${ }^{\mathrm{b}, *}$ \\ ${ }^{a}$ Department of Mechanical Engineering, \\ University of Western Macedonia, 50100, Kozani, Greece \\ ${ }^{\mathrm{b}}$ Department of Technology Management, \\ University of Macedonia, 59200, Naoussa, Greece
}

\begin{abstract}
During the last decades there has been a consistent need for companies to manufacture "green" products in order to contribute to environmental protection. The utilization of used products (literally, the extension of their useful life cycle) is an excellent, indirect way for companies to conform to this requirement and, at the same time, increase their profit. In this paper a Mixed Integer Linear Programming mathematical model is proposed, which can be used for the optimization of procurement, remanufacturing, stocking and salvaging decisions. The model is flexible enough to incorporate multiple suppliers, several quality levels of returned products and multiple periods of time. The applicability of the model is demonstrated through the optimization of alternative scenarios, the optimal solutions of which reveal the potential profitability of used products exploitation.
\end{abstract}

Keywords: Reverse Logistics; Closed-loop supply chains; Remanufacturing; Mixed Integer Linear Programming; Multi-period Model

* Corresponding author. Tel.: +30-23320-52465; fax: +30-23320-52462.

E-mail address: nikolai@uom.gr

Department of Technology Management, University of Macedonia, 59200, Naoussa, Greece 


\section{Introduction}

\subsection{Environmental consciousness and performance measures}

During the last decades, companies all over the world have been strained by a wide range of stakeholders (e.g., customers, investors, regulators, local communities, etc.) to manufacture products that are environmentally friendly in order to contribute to the global, large-scale effort of environmental protection. One way of doing so is through the utilisation of returned products, which extends their useful life cycle.

Lately, the number of environmentally conscious companies is gradually getting bigger and the reason for that is not only that companies are encouraged or even mandated (e.g., by WEEE and RoHS directives) to get involved in reuse activities, but also because it has been made quite clear that the potential profitability of those activities is usually considerably high. Of course, as many researchers

mention (e.g., Kumar and Putnam, 2008, Chung and Wee, 2008), it was the legislation concerning environmental issues that initially led companies to consider their involvement in product recovery activities. However, according to the most contemporary trends, recovery systems should be viewed as a profit centre for companies and not as a cost one.

Many researchers (e.g. Seuring, 2009) have pointed out in the past that the major strategic choices that any manufacturing company has to make to succeed its smooth operation are described by the following key characteristics, which undoubtedly constitute crucial determinants of supply chain performance:

- Product design/engineering issues

- Plant and equipment issues

$\circ$ Organisation and management issues

$\circ \quad$ Labour and staffing issues

- Production planning and control issues.

Similarly, aiming at succeeding the enhancement of their performance, environmental or not, companies engaged in reuse activities need well-designed product recovery strategies. Flapper (2003) claims that the 
latter are strongly influenced by the factors that originally motivated the company to define them, while Fleischmann (2001) states that in order to successfully exploit the opportunities of recovering value from used products, companies need to design a logistics structure that facilitates the optimal management of goods' flows. To this end, decisions need to be taken on how to collect recoverable products from the former user, where to grade collected products in order to separate recoverable resources from scrap, where to reprocess collected products to make them fit for reuse, how to plan capacity and production process (see, for example, Georgiadis and Athanasiou, 2010) and how to distribute recovered products to future customers. More specifically, some indicative strategies suggested by researchers (Pokharel and Mutha, 2009, Guide, 2000 etc.) in establishing effective reverse logistics procedures are the following:

- Location of facilities close to the sources of used products, to disposal sites or even customers

- Increasing availability of resources for reprocessing, for example by exploiting products with small life cycles and large return rates, by accomplishing fast return of used products (perhaps sooner than the end of their life cycle)

- Reducing the structure complexity of products, probably through reengineering of the production process

- Balancing returns with demand and reducing inventories of used (and then remanufactured) products, to counterbalance their quick depreciation.

In response to competitive pressures and the increasing demand of society for more information on the environmental effectiveness of companies, many of them have begun to invent metrics that improve their ability to assess the environmental aspects of their operations. According to the National Academy of Engineering (1999) the measurement of industrial environmental performance is still in its infancy, but it has a high potential for growth because companies wish to progressively increase their metric values and, consequently, their environmental sensitivity. Moreover, one of the principles of the widely implemented environmental management standard ISO 14000 induces companies to measure, monitor, and evaluate their environmental performance.

One widely used scheme classifies metrics in three areas according to their use, i.e., for i) making 
operational decisions, ii) making management decisions and iii) assessing the condition of the (external) environment ${ }^{1}$. Operational metrics generally measure potential environmental burden in terms of inputs and outputs of materials and energy. Frequently used operational metrics are the following:

- Quantity of materials used per unit of product

- Quantity of processed, recycled, or reused materials

- Quantity of packaging materials discarded or reused per unit of product

- Quantity of energy used per year or per unit of product

- Quantity of energy units saved due to energy conservation

- Number of products that can be reused or recycled

Q Quantity of waste per year or per unit of product

- Quantity of specific emissions per year or per unit of product, etc.

Whereas operational metrics provide an indication of the present state of a company's environmental performance, management metrics, like the following, are designed to inform management and support decision making on the expenditure of time, money and manpower required to maintain or improve a company's environmental performance:

- Number of employees whose job descriptions include environmental responsibilities

- Sales revenue attributable to a new product or a by-product designed to meet environmental performance objectives

- Degree of compliance with environmental regulations

- Number of or costs attributable to environmental fines and penalties

- Operational and capital costs associated with a product's or a process' environmental aspects

- Savings achieved through reductions in resource use, pollution prevention, waste recycling, etc.

\footnotetext{
${ }^{1}$ Despite the fact that environmental condition metrics are of great interest to industry and external stakeholders, it is also the area in which the fewest number of robust metrics have been developed and implemented in practice.
} 
Focusing on companies involved in reuse activities, the performance measures that are usually considered (Lieckens and Vandaele, 2007, Prahinski and Kocabasoglu, 2006 etc.) in order to assess reuse activities can be either quantitative or qualitative and among them one can find the following:

- Environmental regulatory compliance

- Improved customer relations

$\circ$ Recovery of assets

- Reduction of production costs

- Improved profitability

- Acceleration of various times, such as the time required to transport returned products from collection centers to recovery facilities, the time spent there (i.e., queue time plus reprocessing time) etc.

Even from the variety of metrics and measures mentioned previously and their cross functional impacts, it is obvious that the complexity of managing reverse logistics processes should not be ignored. The range of issues that need to be taken into consideration is wide, while their understanding could significantly influence managerial decisions and environmental impact (Prahinski and Kocabasoglu, 2006). Three aspects are frequently mentioned as barriers for implementing sustainable supply chains: i) high costs, ii) coordination effort and complexity and iii) insufficient or missing communication in the supply chain (Seuring and Muller, 2008). Many of the complexities mainly arise from the fact that there are important gaps in the research literature of Closed-Loop Supply Chain ${ }^{2}$ (CLSC), like in the areas of inspection, disposition, distribution and selling of remanufactured products (Guide et al., 2003).

\subsection{Product recovery policies and product acquisition management}

The less mature and easier way to exploit returned products is through recycling, which is the simplest procedure of reusing the structural materials of a product. Nevertheless, recycling is a way to benefit from used products, ignoring completely their added value. In some cases, though, returned products may actually be functional and thus, they may be reused (even partially), after some form of repair. For this

\footnotetext{
${ }^{2}$ This is a relatively recent phrase that is used to describe the "loop" that includes the forward supply chain (i.e., selling new products to end-users) as well as the backward supply chain (i.e., receiving returns by end-users).
} 
reason, a more efficient way of producing environmentally friendly products is through the utilization of used devices, if possible, which extends their useful life cycle. There are various options of reuse such as remanufacturing, which is a repair process of the whole product or cannibalization, which is a process that aims at recovering the functional components of the product.

The comprehensive reviews of Guide (2000), Srivastava (2007) and Pokharel and Mutha (2009) reveal the considerable effort that has been allocated by the research community on remanufacturing. The most important business aspects for the effective management of a CLSC are studied in Van Wassenhove and Guide (2002). Guide and Van Wassenhove (2003) present a review and discussion of several areas in CLSC. It is true that most operational aspects of remanufacturing have received the academics' attention, who have provided the research community with numerous articles dealing with inventory control (Van der Laan et al., 1999, Toktay et al., 2000, etc.), materials planning (Inderfurth and Jensen, 1999, Ferrer and Whybark, 2001, etc.) and production planning and control (Guide, 2000, Souza et al., 2002, etc.).

For companies involved in reuse activities, returns are actually their raw materials and thus, the effective management of their acquisition is highly crucial although it has not attracted the interest of many researchers as Guide and Van Wassenhove (2001) point out. Two of the few articles in the area of used product acquisition are the ones of Galbreth and Blackburn (2006) who outline the importance of sorting as the condition of returns is often highly variable and Zikopoulos and Tagaras (2007) who examine procurement and production decisions in reverse supply chains under yield uncertainty. Finally, Nikolaidis (2009) presents a single-period mathematical model for the optimization of decisions regarding procurement and remanufacturing of returns. Our work also focuses mainly on used product acquisition, trying to fill in the aforementioned research gap; actually it extends the model of Nikolaidis (2009) to its multi-period version.

Guide and Van Wassenhove (2001) analytically present and discuss two different systems for obtaining used products from end-users: the waste stream system and the market-driven system. In the context of the first, companies just passively accept any returns of used products and can neither influence the returns quality (or do not wish to influence it) nor acquire returns of a specific quality. Inevitably, 
companies consider returned products as a costly but obligatory procedure and simply try to minimize the consequent losses. Therefore, the waste stream system is adopted only when the acquisition of returns is mandatory.

The market-driven system is more popular among U.S. companies, because most of them have already been persuaded about the profitability of reuse activities, mainly remanufacturing (Guide, 2000). Companies that adopt this system, usually motivate end-users to return products after the end of their life cycle. Moreover, they try to influence the returns quality in various ways, e.g., by offering financial incentives, especially for better quality used products. Thus, it is clear that in market-driven systems the return rate as well as the quality of returns can be influenced by the involved companies and, consequently, they should be regarded as decision variables with wide margins of activation.

Evidently, companies often have to manage used products that are returned either in the waste stream system context or in the market-driven system one. Having that in mind, the main scope of this paper is the presentation of a mathematical model, specifically a Mixed Integer Linear Programming (MILP) one, which may be used by companies as a tool to optimize their decisions regarding the quantities that they should procure, remanufacture, stock and salvage, concerning the amounts of returns as well as their quality level. We consider this as the main contribution of our paper, since the lack of a simple, practical, quantitative tool forces companies to either passively accept or ignore any returns of used products. Besides, the results of the suggested model can be used in various ways for determining useful environmental and, mainly, performance measures. For example, the optimum solution obtained from our model provides the amount of returned products that need to be procured and remanufactured to maximize profit. The ratio of this amount over the new products that are manufactured by a company is a useful measure indicating the level of used products exploitation. Moreover, another simple performance measure is the actual profit derived from all remanufacturing activities (which is optimized through our model) compared to the profit of traditional manufacturing activities or to the turnover of the company.

Regarding our choice to develop a MILP mathematical model, it should be noted that Denizel et al. (2009) mention that the most common research method to develop production plans for both new and 
remanufactured products presumes that the demand for these products is deterministic and solves the mathematical model using a linear programming formulation. The demand uncertainty is typically accounted for by solving the MILP model on a rolling horizon, where the demand forecast is frequently updated and the MILP model is resolved. Moreover, linear programming models have been used before in literature for the optimization of decisions concerning waste and by-product materials (Pourmohammadi et al., 2004), tire remanufacturing (Lebreton and Tuma, 2006), systematic product disassembly (Willems et al., 2006) etc.

The paper is organized in the following manner. In Section 2 we present the definition of the problem and the basic assumptions, while in Section 3 we present the mathematical programming model. In Section 4, through some brief numerical examples and a simulation study we present the use of the model and the optimal solutions regarding various scenarios. The final section summarizes our work, presents some concluding remarks and proposes topics for future research.

\section{Problem definition}

The problem setting concerns any company that offers to its customers high quality remanufactured products, as an economical alternative to new ones. In order to satisfy demand, such a company needs to procure used products. Their procurement may take place at different points of time, thus, the quantity and quality level of returned products is highly variable. Moreover, due to the multi-period context of the problem, the company frequently needs to stock used products and, occasionally, to salvage some of them. So, it becomes clear that the company has plenty of choices for (batches of) used products and has to optimize its decisions concerning procurement, remanufacturing, stocking and salvaging of returns, from an economic point of view.

In Nikolaidis (2009) a MILP model is developed for the optimization of such decisions in a singleperiod context, for the special case of cell phones. However, most of the times, a single-period model is inadequate to describe effectively such a dynamic system. A cursory solution to tackle the multi-period dimension of the problem would be to apply a single-period model - for example the one of Nikolaidis 
(2009) - several times, one for each period of time. Obviously, most of the times, this would not lead to the global optimization of the company's profit. For this reason, in this paper we extend this first attempt and develop a multi-period model for the optimization of procurement, remanufacturing, stocking and salvaging decisions.

In general, one of the challenges in effective, real-world CLSC management is making decisions when facing uncertainty and incomplete information about various issues, such as

○ various costs, i.e., acquisition cost, remanufacturing cost, salvage cost etc.,

- various times, i.e., processing (remanufacturing) time, machines' set-up time, mean time between failures etc. (Jain and Deshmukh, 2009),

- price dynamics, i.e., uncertainties in demand for remanufactured products, offered quantities of returned products, prices, and their interaction,

other issues, like variability in order type, quality of product returns, uncertainties regarding the life cycle of products, flows of information (see Jain et al., 2009) etc.

Therefore, it is essential for any remanufacturing company to be able to cope dynamically with variations in the environment, i.e., demand, supply, inventory, temporal etc. constraints, to overcome disharmonies between production and demand, as well as costly interruption stock-out or over-stock problems.

In our paper we handle the uncertainties in information associated with reverse logistics activities by developing a multi-period MILP model (instead of a single-period one) and by using it in order to conduct a simulation analysis. In this analysis we consider some of the parameters as stochastic, representing them as random variables with specific pdfs. However, several other choices have been made in literature so that uncertainties are faced. Jain and Deshmukh (2009) believe that the application of fuzzy logic and multi-agent system techniques to this problem, seems appropriate. Denizel et al. (2009) consider that stochastic programming is an attractive methodology to face the uncertainty in the quality of returns. Finally, Qin and Ji (2010) present extensively the choices of several researchers who try to deal with uncertainty. 
Summarizing, in our paper we consider that at each period of time the remanufacturing company has to decide whether it should procure all, some, or none of the batches offered by suppliers, which part of these batches should be remanufactured, which part should be stocked to cover future demand and, finally, which part should be salvaged, i.e., sold non-remanufactured in an inferior market. These choices should be made based on economic criteria with regard to the available batches, the returns quality level and the future demand. All these, along with the relative costs and selling prices are assumed to be known a priori. The details of the mathematical model are analytically presented in the following section.

\section{Model development}

The proposed MILP model is developed for a multi-period setting and is related to a specific type of used products (e.g., SGH-E251 Samsung cell phones or Fuji Film A340 4MP digital cameras or HP colour LaserJet $4700 \mathrm{dn}$ printers etc.). In each time period (deal), at least some of the suppliers offer to the remanufacturing company a batch of used products, of a specific quality mix, at a specific price. As in the model of Nikolaidis (2009), we also assume that the quality and the price of returns cannot be influenced by the remanufacturing company. However, we consider that the company knows with accuracy the quality of returned products.

The company has to procure either the whole quantity of an offered batch or nothing. We also consider that there is no disposal, since returned products can be remanufactured regardless of their initial quality level. On the other hand, we assume that a returned product cannot be sold unless it is remanufactured, i.e., even the highest quality products need a minimum amount of rework to be considered "as good as new". Note that there is always the option to salvage used products (without any rework activity) at a relatively low price. Moreover, the MILP model is formulated assuming that the demand of every time period - which is known in advance - should be satisfied in time (no late satisfaction is permitted), while the company has the option to store used products, at a specific holding cost, prior to remanufacturing them. We also assume that any unmet demand for remanufactured products at each period is lost (cannot be satisfied at a future time-period) and burdens the company with a shortage cost. 
Finally, we assume that no remanufacturing takes place unless there is a demand for remanufactured products, i.e., no remanufactured products are stored; if they undergo the remanufacturing process it will be to satisfy the demand.

We assume that there exist $I$ suppliers and the index $i(=1, \ldots, I)$ reflects the identity number of the supplier offering a batch of used products. We use the index $t(=1, \ldots, T)$ to reflect the period during which a deal takes place and the index $j(=1, \ldots, J)$ to reflect the quality level of the returns; the highest quality level is $J$ and the lowest is 1 . The mathematical programming formulation relies on the following parameters:

$\boldsymbol{D E M}_{\boldsymbol{i}}$ : $\quad$ future demand for remanufactured products which should be satisfied at the end of period $t$;

$\boldsymbol{B A T C H} \boldsymbol{H}_{i, t}$ batch size offered by supplier $i$, at period $t$;

$f_{i, j, t}: \quad$ percentage of quality $j$ used units in the batch offered by supplier $i$, at period $t$;

$\boldsymbol{B} \boldsymbol{A T C H Q _ { i , j , t }}$ : quantity of quality $j$ used units in the batch offered by supplier $i$ at period $t$; it is $\mathrm{BATCHQ}_{i, j, t}=f_{i, j, t} \cdot \mathrm{BATCH}_{i, t} \forall i, j, t ;$

selpr $_{t}$ : $\quad$ selling price of a remanufactured product at period $t$;

$\boldsymbol{s a l v p r}_{j, t}$ salvage price (corresponding to the salvage value) of a procured, but nonremanufactured used product in quality level $j$, at period $t$. Evidently, it is $\operatorname{salvpr}_{j, t}<$ $\operatorname{selpr}_{t} \forall j, t$

$\boldsymbol{a c q c}_{i, t}: \quad$ acquisition cost of a used unit offered by from supplier $i$, at period $t$;

fixedc $_{i, t}$ : fixed order cost corresponding to all necessary activities (e.g., ordering, transferring, etc.) that take place when a batch is procured from supplier $i$, at period $t$;

$\boldsymbol{r e m c}_{j, t}: \quad$ remanufacturing cost of a used unit in quality level $j$, at period $t$;

shortc $_{t}$ : $\quad$ shortage cost per unit of unsatisfied demand at period $t$;

$\boldsymbol{h o l d c}_{j, t}$ : holding cost of a used unit in quality level $j$, at period $t$;

$\boldsymbol{I N} \boldsymbol{V}_{j, 0}$ : $\quad$ initial inventory of quality level $j$ used units, just before the beginning of period 1 ; 
$\boldsymbol{B U D G} \boldsymbol{G}_{t}: \quad$ available budget for a specific deal at period $t$;

CAPACITY: maximum amount of units that can be stored in the company's warehouse.

The decision variables of the model are the following:

$y_{i, t}$ binary variable which reflects the choice of the remanufacturing company to procure or not the batch offered by supplier $i$, at period $t$ : $y_{i, t}=\left\{\begin{array}{l}1 \text { if the company should order the quantity } B A T C H_{i, t} \\ 0 \text { if the company should not order the quantity } B A T C H_{i, t}\end{array} ;\right.$

$\boldsymbol{x}_{i, j, t}$ : $\quad$ fraction of the quantity $B A T C H Q_{i, j, t}$ offered by supplier $i$ (corresponding to quality level $j$ used units), at period $t$, which should be remanufactured; it is $0 \leq x_{i, j, t} \leq 1 \quad \forall i, j, t$;

$\boldsymbol{I N} \boldsymbol{V}_{j, t}: \quad$ inventory of quality level $j$ used units, at the end of period $t$;

$\operatorname{INVREM}_{j, t}$ : $\quad$ amount of the inventory $I N V_{j, t-1}$ (corresponding to quality level $j$ used units) which should be remanufactured and sold at period $t$; it is $0 \leq I N V R E M_{j, t} \leq I N V_{j, t-1} \forall j, t$;

$\boldsymbol{S} \boldsymbol{A} \boldsymbol{L} \boldsymbol{V}_{j, 0}$ : $\quad$ quantity of quality level $j$ used products that should be salvaged just before the beginning of period 1 .

$\boldsymbol{S} \boldsymbol{A} \boldsymbol{L} \boldsymbol{V}_{j, t}$ : quantity of quality level $j$ used products that should be salvaged at the end of period $t$.

The following variables are also introduced to the modelling of the problem:

Profit: total profit of the remanufacturing company, which includes the opportunity (shortage) cost as well;

$\boldsymbol{R E M Q _ { j , t }} \quad$ quantity of quality $j$ used units which should be remanufactured and sold, at period $t$; $\boldsymbol{R E M}$ : $\quad$ total quantity of used products which should be remanufactured and sold at period $t$. It is calculated by:

$$
R E M_{t}=\sum_{j=1}^{J} R E M Q_{j, t} \quad \forall t
$$

Figure 1 represents how the various quantities interact during period $t$, regarding the time when the various events occur, as well as the nature of these quantities, i.e., whether they constitute "incoming" or 
"outgoing" quantities of the system (upward and downward arrows respectively). Therefore, at the beginning of any but the first period $t$, there are inventories $I N V_{j, t-1} \forall j$ of non-remanufactured products of quality level $j$, a part of which, namely $\operatorname{INVREM}_{j, t} \forall j$, will be remanufactured - and sold - at the current period $(t)$, while the rest of the inventories, namely $I N V_{j, t-1}-I N V R E M_{j, t} \forall j$, are added to the inventory that will be kept at the end of the current period $\left(I N V_{j, t}\right)$. At the same time the company procures one or more batches of $\mathrm{BATCH}_{i, t}$ used products. Bear in mind that every batch contains used products at a quality mix. Then, the company remanufactures $R E M_{t}$ units and satisfies the whole - or part of the - demand $D E M_{t}$ of this period. At the end of period $t$ the company decides which part of the probable excess of used products in each quality level $j$, is going to be salvaged $\left(S A L V_{j, t} \forall j\right)$ and which will constitute the inventory $I N V_{j, t} \forall j$ of the following period.

\section{Figure 1 about here}

Especially for the first period ( $t=1)$, the figure must be slightly adjusted (Figure 2), due to a usually necessary preliminary work of the remanufacturer, just before the beginning of this period. The company should decide if the initial inventories $I N V_{j, 0} \forall j$ are extremely large and a part of them $\left(S A L V_{j, 0}, \forall j\right)$ should be salvaged immediately (dotted arrow). For this reason, the "incoming" quantity of the first period (upward arrow) equals the initial inventory minus the quantity that should be salvaged $\left(I N V_{j, 0}-S A L V_{j, 0}\right.$ $\forall j$ ). Then the operation of the system continues as it was described previously.

\section{Figure 2 about here}

The objective function of the MILP formulation, which expresses the total profit and should obviously be maximized, has the following form:

$$
\begin{aligned}
\max \text { Profit } & \sum_{t=1}^{T} \operatorname{selpr}_{t} \cdot \text { REM }_{t}+\sum_{j=1}^{J} \operatorname{salvpr}_{j, 0} \cdot \operatorname{SALV}_{j, 0}+\sum_{t=1}^{T} \sum_{j=1}^{J} \operatorname{salvpr}_{j, t} \cdot \operatorname{SALV}_{j, t} \\
& -\sum_{t=1}^{T} \sum_{i=1}^{I} \text { fixed }_{i, t} \cdot y_{i, t}-\sum_{t=1}^{T} \sum_{i=1}^{I} a c q c_{i, t} \cdot \text { BATCH }_{i, t} \cdot y_{i, t}-\sum_{t=1}^{T} \sum_{j=1}^{J} r e m c_{j, t} \cdot \operatorname{REMQ}_{j, t} \\
& -\sum_{j=1}^{J} \text { holdc }_{j, 0} \cdot\left(I N V_{j, 0}-S A L V_{j, 0}\right)-\sum_{t=1}^{T} \sum_{j=1}^{J} \text { holdc }_{j, t} \cdot I N V_{j, t}-\sum_{t=1}^{T} \operatorname{shortc}_{t} \cdot\left(\text { DEM }_{t}-\text { REM }_{t}\right) .
\end{aligned}
$$


The first three terms of (2) represent the company's revenue from selling the remanufactured units, as well as from salvaging the non-remanufactured ones. The negative terms that follow, correspond to the fixed order cost, the acquisition cost, the remanufacturing cost, the holding cost of the initial inventory as well as for periods $t=1, \ldots, T$ and the shortage cost, respectively.

The objective function is subject to the following constraints:

$$
\begin{aligned}
& x_{i, j, t} \leq y_{i, t} \quad \forall i, j, t \\
& R E M_{t} \leq D E M_{t} \quad \forall t \\
& \text { BATCHQ }_{i, j, t}=f_{i, j, t} \cdot \mathrm{BATCH}_{i, t} \quad \forall i, j, t \\
& R E M Q_{j, t}=\sum_{i=1}^{I} B A T C H Q_{i, j, t} \cdot x_{i, j, t}+\operatorname{INVREM}_{j, t} \quad \forall j, t \\
& \operatorname{INVREM}_{j, 1} \leq I N V_{j, 0}-S A L V_{j, 0} \quad \forall j \\
& \operatorname{INVREM}_{j, t} \leq I N V_{j, t-1} \quad \forall j \text { and } t \geq 2 \\
& I N V_{j, 1}=\sum_{i=1}^{I} B A T C H Q_{i, j, 1} \cdot\left(y_{i, 1}-x_{i, j, 1}\right)+I N V_{j, 0}-S A L V_{j, 0}-{I N V R E M_{j, 1}}-S A L V_{j, 1} \quad \forall j \\
& I N V_{j, t}=\sum_{i=1}^{I} B A T C H Q_{i, j, t} \cdot\left(y_{i, t}-x_{i, j, t}\right)+I N V_{j, t-1}-\operatorname{INVREM}_{j, t}-S A L V_{j, t} \quad \forall j \text { and } t \geq 2 \\
& y_{i, t}: \text { binary } \forall i, t \\
& R E M Q_{j, t} \text { : integer } \forall j, t \\
& I N V_{j, t}: \text { integer } \forall j, t \\
& S A L V_{j, t} \text { : integer } \forall j, t
\end{aligned}
$$

as well as (1). The objective function may also be subject to cash flow constraints of the type:

$$
\begin{aligned}
B U D G_{1}= & B U D G_{0}+\operatorname{selpr}_{1} \cdot R E M_{1}+\sum_{i=0}^{1} \sum_{j=1}^{J} \operatorname{salvpr}_{j, t} \cdot S A L V_{j, t}-\sum_{i=1}^{I} \text { fixedc }_{i, 1} \cdot y_{i, 1} \\
& -\sum_{i=1}^{I} a c q c_{i, 1} \cdot \text { BATCH }_{i, 1} \cdot y_{i, 1}-\sum_{j=1}^{J} r e m c_{j, 1} \cdot R E M Q_{j, 1}
\end{aligned}
$$




$$
\begin{gathered}
B U D G_{t}=B U D G_{t-1}+\operatorname{selpr}_{t} \cdot R E M_{t}+\sum_{j=1}^{J} \operatorname{salvpr}_{j, t} \cdot S A L V_{j, t}-\sum_{i=1}^{I} \text { fixedc }_{i, t} \cdot y_{i, t} \\
-\sum_{i=1}^{I} a c q c_{i, t} \cdot B A T C H_{i, t} \cdot y_{i, t}-\sum_{j=1}^{J} r e m c_{j, t} \cdot R E M Q_{j, t} \\
B U D G_{t} \geq 0 \quad \forall t
\end{gathered}
$$

where $B U D G_{0}$ is given. It may also be subject to budget constraints of the type:

$$
\sum_{i=1}^{I} \operatorname{fixedc}_{i, t} \cdot y_{i, t}+\sum_{i=1}^{I} a c q c_{i, t} \cdot \mathrm{BATCH}_{i, t} \cdot y_{i, t}+\sum_{j=1}^{J} \operatorname{remc}_{j, t} \cdot \operatorname{REMQ}_{j, t} \leq B U D G_{t-1} \quad \forall t
$$

The objective function could also be subject to storage constraints of the type:

$$
\sum_{j=1}^{J} I N V_{j, t} \leq \text { CAPACITY } \quad \forall t
$$

and

$$
\sum_{j=1}^{J}\left(I N V_{j, 0}-S A L V_{j, 0}\right) \leq C A P A C I T Y
$$

Constraints (3) ensure that if the remanufacturing company does not order the batch offered by supplier $i$ (i.e., $y_{i, t}=0$ ), then evidently, there will not be any remanufactured products from this batch (i.e., $x_{i, j, t}=0 \forall j$ ). Constraints (4) impose that used products are remanufactured only if they are to be sold. Constraints (5) divide each batch to sub-batches of different quality. Constraints (6), (9) and (10) are used to compute the remanufacturing and inventory quantities, while constraints (7) and (8) impose the amount of inventory that will be remanufactured and sold at each period to not exceed the actual inventory in stock. Constraints (11) assure that the decision variables $y_{i, t}$ are binary and in the same way, constraints (12) to (14) assure that the quantities that will be remanufactured, stocked and salvaged respectively, should be integer. Constraints (15) to (20) are auxiliary and may be included in the model, depending on the individual physiognomy of the company (and the products) under study.

The programming code (written for LINGO 9.0 software) that has been developed for the solution of the suggested model is presented in the Appendix, for an indicative set of parameters and variables, 
without the auxiliary constraints (15) to (20).

\section{Illustrative examples}

In this section we present some indicative numerical examples. It should be noted that the potential sets of costs, prices, demand rates, periods of time, etc. are practically infinite. Consequently, the scope of these examples is certainly not to investigate all possible alternatives for each of the parameters of the model, but

i) to highlight the model operation,

ii) to illustrate the form of the optimal solutions,

iii) to present some scenarios that could exist in real life applications, e.g., as shown in Nikolaidis (2009),

iv) to illustrate that through the use of our model, it is relatively easy to optimize economically the decisions of procurement, remanufacturing, salvaging and stocking, and finally

iii) to present the superiority of the suggested model over the alternative of applying a single-period model multiple times in order to optimize the aforementioned decisions.

In all examples we assume that there is unlimited initial budget and no capacity limitations, thus, constraints (15) to (20) are redundant. Additionally, we assume that there are three periods of time, i.e., $T$

$=3$, three alternative suppliers, i.e., $I=3$, six different quality levels of returns, i.e., $J=6$, and that there is no initial inventory, i.e., $I N V_{j, 0}=0 \forall j$. We illustrate the operation of the model and we define its optimal solution through alternative scenarios.

The parameter values of Scenario 1 are presented in Table 1. Note that the choice of these values is made in order to achieve the aims i) and ii) mentioned previously without necessarily having in mind any particular type of product. According to this scenario, we consider that the revenue from selling a remanufactured item is 15,14 and $13 €$, while the acquisition cost is 5,4 and $3 €$ regardless of the supplier, for $t=1,2$ and 3 respectively. Similarly, we assume that the demand for remanufactured products per period is 900,800 and 700 items, while the shortage cost is $4,3.5$ and $3 €$ respectively. The cost of remanufacturing a used item is $10,9,8,7,6$ and $5 €$ for a used product of quality $j=1,2,3,4,5$ 
and 6 respectively. It is also assumed that the first supplier $(i=1)$ provides the company with uniformly high quality products, i.e., $f_{1,3, t}=f_{1,4, t}=f_{1,5, t}=f_{1,6, t}=0.25 \forall t$. The second supplier $(i=2)$ is assumed to have a very mixed collection of products; most products show average wear, a few are in very poor condition and a few are in an almost perfect condition, i.e., $f_{2,1, t}=0.10, f_{2,2, t}=0.15, f_{2,3, t}=0.25, f_{2,4, t}=0.25$, $f_{2,5, t}=0.15, f_{2,6, t}=0.10 \forall t$. Finally, we assume that the third supplier $(i=3)$ deals with commercial contracts, where the products may have been heavily used and not maintained, consequently, fairly poor quality products are offered, i.e., $f_{3,1, t}=f_{3,2, t}=f_{3,3, t}=f_{1,4, t}=0.25 \forall t$.

We also assume that the fixed cost is $50 €$ for every supplier and period, the salvage price is $3 €$ and the holding cost is $0.1 €$ per item. Finally, the offered batch size is 300 items per period for supplier 1, 400 items per period for supplier 2 and 500 for supplier 3.

\section{Table 1 about here}

In Table 2 we briefly present the optimal solution of Scenario 1. In particular, we see that the optimal total profit of the multi-period model derived from (2), i.e., $P_{M P M}$, equals to $6,740 €$ and that the remanufacturing company should buy all offers except for the offer of supplier 1 at period 3 . According to this solution, a large number of items should be salvaged, while the inventory that should be kept is very low. More specifically, the company should salvage 300, 350 and 250 items for periods $t=1,2$ and 3 respectively and store 50 items at the end of period $t=2$. It is interesting to notice that all salvaged products should be of quality $j=1$ or 2 , i.e., of low quality level. This is an absolutely reasonable result as it has been assumed that the company earns the same from salvaging products regardless of their quality level, while at the same time it has been assumed that the remanufacturing cost is higher when quality is low. Similarly, since we assume that the holding cost is the same for all products regardless of their quality level, we notice that the inventory that needs to be kept under the optimal solution (at period $t=2$ ), is of the highest quality. i.e., $j=6$.

\section{Table 2 about here}

Apart from Scenario 1, we apply our model to situations that differ from this scenario by a single 
parameter. In particular, Scenario 2 differs from Scenario 1 in that the salvage price is considered to be $5 €$ instead of $3 €$. In Scenario 3 we use fixed $_{i, t}=1,000 €($ instead of $50 €)$, while in Scenario 4 we set $D E M_{1}$ $=900, D E M_{2}=1,200$ and $D E M_{3}=1,500$. In Table 3 we present all scenarios, their differences compared to Scenario 1, as well as the optimal total profit of every examined scenario. We also present the profit that would be derived if instead of the current multi-period model we used the respective single-period model for each of the $t=3$ separate periods, i.e., $P_{S P M}$. To find the optimal solution of the single-period version of the problem, we solved the multi-period model three times, namely for $t=1$ and, then, 2 and 3 , keeping each time the parameters of the other two periods equal to zero. In the last column of Table 3 we present the percentage total profit increase of using the model presented in this paper, i.e., $\Delta P=\frac{P_{M P M}-P_{S P M}}{P_{S P M}} \times 100 \%$, instead of the repetitive implementation of the single period model.

\section{Table 3 about here}

As we see in Table 3, the total profit is always increased when using the multi-period model instead of dealing separately with each of the examined 3 periods. In particular the differences may be negligible (Scenarios 1 and 2) or very significant (Scenarios 3 and 4). In Scenario 2, the increased salvage price (compared to Scenario 1) leads to the decision to buy all offered batches and salvage the excess of procured used products. Thus, the total profit is the same no matter which model is used to tackle the problem. On the other hand, in Scenarios 3 and 4, the optimal solutions obtained from the multi-period model are far more superior to any other solutions.

It should be noted once again that the average profit improvements are not conclusive. Obviously, the purpose of the numerical investigation presented so far is not to draw solid conclusions on the effectiveness of our model; after all, the model incorporates so many parameters and variables that any attempt to investigate thoroughly all alternatives would be certainly doomed to failure.

However, apart from the four aforementioned scenarios, we conduct a simulation analysis where most of the parameters of our model are randomly generated from specific probability distributions. In particular, the value of the demand for remanufactured products in each of the three periods of time and at 
each simulation run is generated from a normal distribution with a mean $\mu$ equal to 200 units and a standard deviation $\sigma$ equal to 40 units. Moreover, the values of $B A T C H_{i, t}$ are provided by a normal distribution with $\mu=100$ and $\sigma=20$. Apart from these parameters, the values of the selling price of a remanufactured product selpr $r_{t}$ and the values of the shortage cost per unit of unsatisfied demand shortc $_{t}$ are drawn from the following uniform distributions $\mathrm{U}(80,120)$ and $\mathrm{U}(20,50)$ respectively. In all simulation runs we use - for every $t$ - holdc $c_{j, t}$ equal to $0.1,0.4,0.7,1.0,1.3$ and 1.6 for $j=1$ to 6 respectively, since the higher the value of $j$, the more expensive the item and thus, the more expensive to store it. In the same sense we set - for every $t$ - $\operatorname{salvpr}_{j, t}$ equal to $10,12,14,16,18$ and 20 and $r e m c_{j, t}$ equal to $50,45,40,35,30$ and 25 for $j=1$ to 6 respectively. The aforementioned choices on the parameter values are based on the work of Denizel et al. (2009) and on the real data presented in Ferguson et al. (2009) as collected at Pitney-Bowes from the remanufacturing activities regarding their mailing systems.

The results of 1,000 simulation runs indicate that the profit increase when using the multi-period model is $4 \%$ on average while it can even be higher than $60 \%$. Figure 3 illustrates the frequency distribution of $\Delta P$.

\section{Figure 3 about here}

In Figure 4 below we illustrate the relationship between the average total inventory and $\Delta P$. It is clear that when the optimum solution leads to high inventories, the percentage improvement of our model increases as it is the multi-period model that allows transferring inventories from one period of time to the next.

\section{Figure 4 about here}

In Figure 5 we illustrate the level of the average inventory, selling price and shortage cost of the system for different levels of profit improvement of the multi-period model. The improvement $\Delta P$ is relatively high when the optimum solution leads to high inventories (see also Figure 4). On the other hand, small percentage profit improvements are noticed for higher average selling prices. This is a reasonable finding as the selling price gets higher the percentage improvement decreases because the denominator in 
the ratio of improvement, namely $P_{S P M}$, increases. Finally, slightly larger profit improvements are noticed for higher shortage costs as the new model allows stocking in order to avoid shortages.

\section{Figure 5 about here}

\section{Summary and conclusions}

In this paper we present a new MILP model for the optimization of the decisions of a remanufacturing company concerning procurement, remanufacturing, salvaging and stocking (batches of) used products, for multiple periods of time. The model is flexible enough to be used for various suppliers, returned products of multiple quality levels and, of course, for more than one time periods. Through numerical investigation it is clearly shown that the potential profitability of using the suggested model over the simple alternative of using multiple times a single-period model may be substantial.

We strongly believe that although the MILP model presented in this paper was originally motivated by the case of the returns and remanufacturing of used cell phones, it can be also be used in various other systems. However, an undoubted limitation of our research is that we have not checked empirically this belief and, perhaps, for some kind of products, necessary modifications should be adopted.

Overall, it is worth mentioning that besides the worldwide sensitization of producing environmentally friendly products, the involvement of a company in reuse activities, may also result in increased profitability. Therefore, it should be emphatically highlighted that this involvement leads to a win-win situation since, apart from the obvious environmental benefits, there is also a potentially wide economic gain margin.

Interesting future research directions would include the incorporation of multiple types of returned products in the model or the relaxation of some of the constraints (or/and the objective function) raising the linearity assumption. It would also be interesting to implement the proposed model in real-life applications and discuss the resulting optimal policies with respect to the actual problem parameters. 


\section{References}

Chung, C.-J. and Wee, H.-M., 2008. Green-component Life-cycle Value on Design and Reverse Manufacturing in Semi-closed Supply Chain, International Journal of Production Economics, 113 (2), $528-545$.

Denizel, M., Ferguson, M., and Souza, G.C., 2009, Multi-Period Remanufacturing Planning with Uncertain Quality of Inputs, IEEE Transactions on Engineering Management, article in press.

Directive 2002/95/EC of the European Parliament and of the Council of 27 January 2003 on the restriction of the use of certain hazardous substances in electrical and electronic equipment (RoHS).

Directive 2002/96/EC of the European Parliament and of the Council of 27 January 2003 on waste electrical and electronic equipment (WEEE).

Ferguson, M., Guide Jr., V.D., Koca, E., and Van Souza, G.C., 2009. The Value of Quality Grading in Remanufacturing. Production and Operations Management, 18 (3), 300-314.

Ferrer, G. and Whybark, C., 2001. Material Planning for a Remanufacturing Facility. Production and Operations Management, 10 (2), 112-124.

Flapper, S.D., 2003. Product recovery strategies. In Business aspects of closed-loop chains: Exploring the Issues, Carnegie Bosch Institute, Carnegie Mellon University Press, 71-92.

Fleischmann, M., 2001. Reverse logistics network structures and design. Management Report Series 2001-52-LIS, Erasmus University Rotterdam, The Netherlands.

Galbreth, M.R. and Blackburn, J.D., 2006. Optimal Acquisition and Sorting Policies for Remanufacturing. Production and Operations Management, 15 (3), 384-392.

Georgiadis, P. and Athanasiou, E. 2010. The Impact of Two-Product Joint Lifecycles on Capacity Planning of Remanufacturing Networks, European Journal of Operational Research, 202 (2), 420433.

Guide Jr., V.D.R., 2000. Production Planning and Control for Remanufacturing. Journal of Operations Management, 18 (4), 467-483.

Guide Jr., V.D.R., Teunter, R.H. and Van Wassenhove, L.N., 2003. Matching Demand and Supply to 
Maximize Profits from Remanufacturing. Manufacturing \& Service Operations Management, 5 (4), 303-316.

Guide Jr., V.D.R. and Van Wassenhove, L.N., 2001. Managing Product Returns for Remanufacturing. Production and Operations Management, 10 (2), 142-155.

Guide Jr., V.D.R. and Van Wassenhove, L.N., eds. 2003. Business Aspects of Closed - Loop Supply Chains. Carnegie Mellon University Press, Pittsburg, PA.

Inderfurth, K. and Jensen, T., 1999. Analysis of MRP Policies with Recovery Options, In: U. LeopoldWildburger et al., eds. Modeling and Decisions in Economics. Physica, Heidelberg, Germany, 189228.

Jain, V., and Deshmukh, S.G., 2009. Dynamic Supply Chain Modeling using a New Fuzzy Hybrid Negotiation Mechanism, International Journal of Production Economics, 122 (1), 319-328.

Jain, V., Wadhwa, S. and Deshmukh, S.G., 2009. Revisiting Information Systems to Support a Dynamic Supply Chain: Issues and Perspectives, Production Planning \& Control, 20 (1), 17-29.

Kumar, S, and Putnam, V., 2008. Cradle to Cradle: Reverse Logistics Strategies and Opportunities across Three Industry Sectors, International Journal of Production Economics, 115 (2), 305-315.

Lebreton, B. and Tuma, A., 2006. A Quantitative Approach to Assessing the Profitability of Car and Truck Tire Remanufacturing. International Journal of Production Economics, 104 (2), 639-652.

Lieckens, K. and Vandaele, N., 2007. Reverse Logistics Network Design with Stochastic Lead Times, Computers \& Operations Research, 34 (2), 395-416.

National Academy of Engineering, 1999. Industrial Environmental Performance Metrics: Challenges and Opportunities.

Nikolaidis, Y., 2009. A modelling framework for the acquisition and remanufacturing of used products. International Journal of Sustainable Engineering, 2 (3), 154-170.

Pokharel, S. and Mutha, A., 2009. Perspectives in Reverse Logistics: a Review. Resources, Conservation and Recycling, 53 (4), 175-182.

Pourmohammadi, H., Rahimi, M. and Dessouky, M., 2004. Green logistics for regional industrial waste 
material and by-products. IIE Annual Conference and Exhibition. 1585-1590.

Prahinski, C. and Kocabasoglu, C., 2006. Empirical Research Opportunities in Reverse Supply Chains, Omega, 34 (6), 519-532.

Qin Z. and Ji, X., 2010. Logistics Network Design for Product Recovery in Fuzzy Environment, European Journal of Operational Research, 202 (2), 479-490.

Seuring, S., 2009. The Product-Relationship-Matrix as Framework for Strategic Supply Chain Design based on Operations Theory, International Journal of Production Economics, 120 (1), 221-232.

Seuring, S. and Müller, M., 2008. From a Literature Review to a Conceptual Framework for Sustainable Supply Chain Management, Journal of Cleaner Production, 16 (15), 1699-1710.

Souza, G., Ketzenberg, M. and Guide Jr., V.D.R., 2002. Capacitated Remanufacturing with Service Level Constraints. Production and Operations Management, 11 (2), 231-248.

Srivastava, S.K., 2007. Green supply-chain management: A state-of-the-art literature review. International Journal of Management Reviews, 9 (1), 53-80.

Toktay, B., Wein, L. and Stefanos, Z., 2000. Inventory Management of Remanufacturable Products. Management Science, 46 (11), 1412-1426.

Van der Laan, E., Salomon, M., Dekker, R. and Van Wassenhove, L.N., 1999. Inventory Control in Hybrid Systems with Remanufacturing. Management Science, 45 (5), 733-747.

Van Wassenhove, L.N. and Guide Jr., V.D.R., 2002. Closed - Loop Supply Chains. In: R. Ayres, L. Ayres, eds. A Handbook of Industrial Ecology. Edward Elgar, Northampton, MA, 497-509.

Willems, B., Dewulf, W., and Duflou, J.R., 2006. Can large-scale disassembly be profitable? A linear programming approach to quantifying the turning point to make disassembly economically viable. International Journal of Production Research, 44 (6), 125-1146.

Zikopoulos, C. and Tagaras, G., 2007. Impact of uncertainty in the quality of returns on the profitability of a single-period refurbishing operation. European Journal of Operational Research, 182 (1), 205-225. 


\section{Appendix: Program Code in Lingo 9.0 Format}

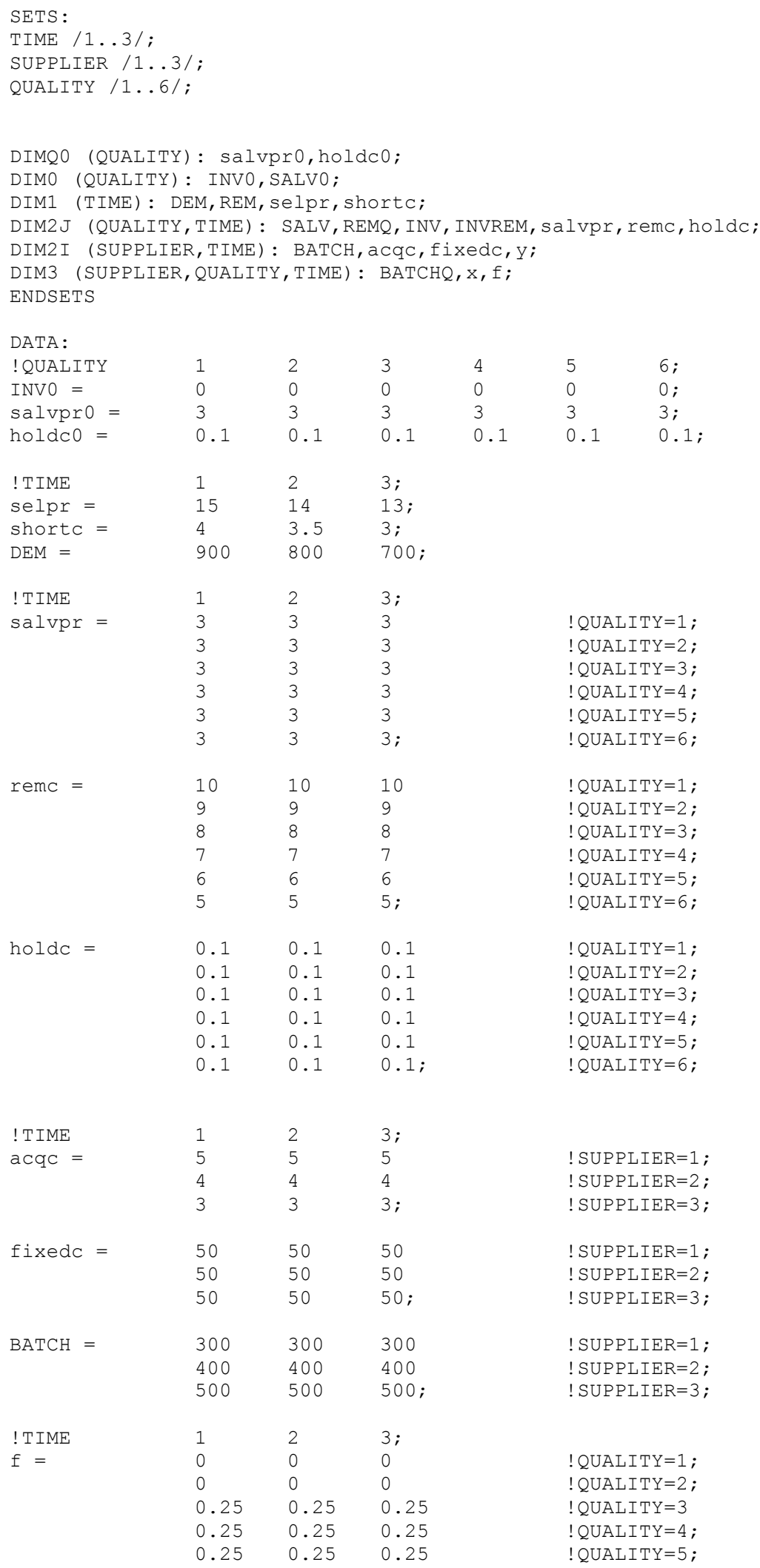

3

$\begin{array}{lll}1 & 2 & 3 ; \\ 0 & 0 & 0 \\ 0 & 0 & 0 \\ 0.25 & 0.25 & 0.25 \\ 0.25 & 0.25 & 0.25 \\ 0.25 & 0.25 & 0.25\end{array}$




\begin{tabular}{|c|c|c|c|c|}
\hline 0.25 & 0.25 & 0.25 & ! QUALITY=6; & \\
\hline 0.1 & 0.1 & 0.1 & ! QUALITY $=1 ;$ & \\
\hline 0.15 & 0.15 & 0.15 & ! QUALITY=2; & \\
\hline 0.25 & 0.25 & 0.25 & ! QUALITY=3 & SUPPLIER $=2$; \\
\hline 0.25 & 0.25 & 0.25 & ! QUALITY=4; & \\
\hline 0.15 & 0.15 & 0.15 & ! QUALITY $=5 ;$ & \\
\hline 0.1 & 0.1 & 0.1 & ! QUALITY=6; & \\
\hline 0.25 & 0.25 & 0.25 & ! QUALITY=1; & \\
\hline 0.25 & 0.25 & 0.25 & ! QUALITY=2; & \\
\hline 0.25 & 0.25 & 0.25 & ! QUALITY=3 & SUPPLIER=3; \\
\hline 0.25 & 0.25 & 0.25 & ! QUALITY=4; & \\
\hline 0 & 0 & 0 & ! QUALITY=5; & \\
\hline 0 & 0 & $0 ;$ & ! QUALITY=6; & \\
\hline
\end{tabular}

ENDDATA

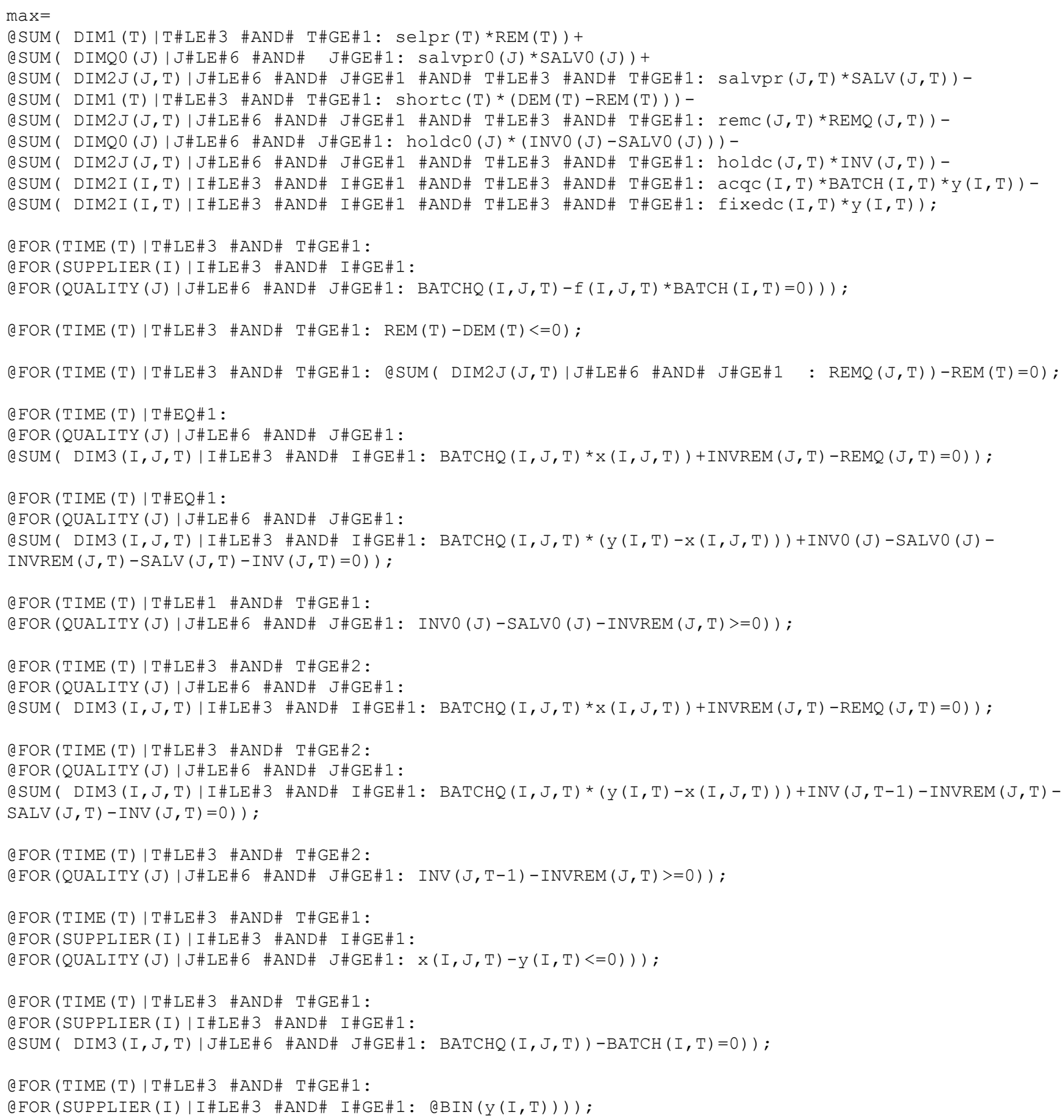


@FOR (TIME (T) | T\#LE\#3 \#AND\# THGE\#1:

@FOR (QUALITY (J) |J\#LE\#6 \#AND\# J\#GE\# 1: @GIN(REMQ (J,T))));

@FOR (TIME (T) IT\#LE\#3 \#AND\# T\#GE\# 1 :

@FOR (QUALITY (J)।J\#LE\#6 \#AND\# J\#GE\#1: $\operatorname{egIN}(\operatorname{INV}(\mathrm{J}, \mathrm{T}))$ )) );

@FOR (TIME (T) |T\#LE\#3 \#AND\# T\#GE\#1:

@FOR (QUALITY (J) |J\#LE\#6 \#AND\# J\#GE\#1: @GIN(INVREM(J,T)))) ;

@FOR (QUALITY (J)।J\#LE\#6 \#AND\# J\#GE\#1: @GIN(SALVO (J)));

QFOR (TIME (T) |T\#LE\# 3 \#AND\# T\#GE\#1:

@FOR (QUALITY (J) | J\#LE\#6 \#AND\# J\#GE\#1: @GIN(SALV(J,T))));

END 


\section{Tables and Figures}

Table 1: Parameter values of Scenario 1

\begin{tabular}{|c|c|c|c|c|c|c|}
\hline time $t$ & \multicolumn{2}{|c|}{1} & \multicolumn{2}{|c|}{2} & \multicolumn{2}{|c|}{3} \\
\hline $\operatorname{selpr}_{t}$ & \multicolumn{2}{|c|}{15} & \multicolumn{2}{|c|}{14} & \multicolumn{2}{|c|}{13} \\
\hline $\operatorname{acqc}_{i, t}(\forall i)$ & \multicolumn{2}{|c|}{5} & \multicolumn{2}{|c|}{4} & \multicolumn{2}{|c|}{3} \\
\hline$D E M_{t}$ & \multicolumn{2}{|c|}{900} & \multicolumn{2}{|c|}{800} & \multicolumn{2}{|c|}{700} \\
\hline shortc $_{t}$ & \multicolumn{2}{|c|}{4} & \multicolumn{2}{|c|}{3.5} & \multicolumn{2}{|c|}{3} \\
\hline quality $j$ & 1 & 2 & 3 & 4 & 5 & 6 \\
\hline $\operatorname{remc}_{j, t}(\forall t)$ & 10 & 9 & 8 & 7 & 6 & 5 \\
\hline$f_{1, j, t}(\forall t)$ & 0 & 0 & 0.25 & 0.25 & 0.25 & 0.25 \\
\hline$f_{2, j, t}(\forall t)$ & 0.1 & 0.15 & 0.25 & 0.25 & 0.15 & 0.1 \\
\hline$f_{3, j, t}(\forall t)$ & 0.25 & 0.25 & 0.25 & 0.25 & 0 & 0 \\
\hline supplier $i$ & \multicolumn{2}{|c|}{1} & \multicolumn{2}{|c|}{2} & \multicolumn{2}{|c|}{3} \\
\hline$B A T C H_{i, t}(\forall t)$ & \multicolumn{2}{|c|}{300} & \multicolumn{2}{|c|}{400} & \multicolumn{2}{|c|}{500} \\
\hline \multicolumn{3}{|c|}{ fixed $_{i, t}=50 \forall i, t$} & \multicolumn{4}{|c|}{$\operatorname{hold}_{j, t}=0.1 \forall j, t$} \\
\hline \multicolumn{3}{|c|}{$\operatorname{salvpr}_{j, t}=3 \forall j, t$} & \multicolumn{4}{|c|}{$I N V_{j, 0}=0 \forall j$} \\
\hline
\end{tabular}


Table 2: Optimal solution of Scenario 1

\begin{tabular}{|c|c|c|c|c|c|c|c|c|c|}
\hline \multirow{2}{*}{\multicolumn{2}{|c|}{ Profit $=6,740 €$}} & \multicolumn{3}{|c|}{$B A T C H Q_{i, j, t} y_{i, t}$} & \multirow{3}{*}{$\begin{array}{c}\begin{array}{c}\text { Total Procurement } \\
\text { quantities }\end{array} \\
165\end{array}$} & \multirow{2}{*}{$\operatorname{DEM}_{t}$} & \multirow{2}{*}{$R E M Q_{j, t}$} & \multirow{2}{*}{$I N V_{j, t}$} & \multirow{2}{*}{$S A L V_{j, r}$} \\
\hline & & $i=1$ & $i=2$ & $i=\mathbf{3}$ & & & & & \\
\hline \multirow{7}{*}{$t=1$} & $j=1$ & 0 & 40 & 125 & & \multirow{7}{*}{900} & 0 & 0 & 165 \\
\hline & $j=2$ & 0 & 60 & 125 & 185 & & 50 & 0 & 135 \\
\hline & $j=\mathbf{3}$ & 75 & 100 & 125 & 300 & & 300 & 0 & 0 \\
\hline & $j=4$ & 75 & 100 & 125 & 300 & & 300 & 0 & 0 \\
\hline & $j=\mathbf{5}$ & 75 & 60 & 0 & 135 & & 135 & 0 & 0 \\
\hline & $j=6$ & 75 & 40 & 0 & 115 & & 115 & 0 & 0 \\
\hline & total & 300 & 400 & 500 & 1200 & & 900 & 0 & 300 \\
\hline \multirow{7}{*}{$t=2$} & $j=1$ & 0 & 40 & 125 & 165 & \multirow{7}{*}{800} & 0 & 0 & 165 \\
\hline & $j=2$ & 0 & 60 & 125 & 185 & & 0 & 0 & 185 \\
\hline & $j=3$ & 75 & 100 & 125 & 300 & & 300 & 0 & 0 \\
\hline & $j=4$ & 75 & 100 & 125 & 300 & & 300 & 0 & 0 \\
\hline & $j=5$ & 75 & 60 & 0 & 135 & & 135 & 0 & 0 \\
\hline & $j=6$ & 75 & 40 & 0 & 115 & & 65 & 50 & 0 \\
\hline & total & 300 & 400 & 500 & 1200 & & 800 & 50 & 350 \\
\hline \multirow{7}{*}{$t=\mathbf{3}$} & $j=1$ & - & 40 & 125 & 165 & \multirow{7}{*}{700} & 0 & 0 & 165 \\
\hline & $j=2$ & - & 60 & 125 & 185 & & 100 & 0 & 85 \\
\hline & $j=\mathbf{3}$ & - & 100 & 125 & 225 & & 225 & 0 & 0 \\
\hline & $j=4$ & - & 100 & 125 & 225 & & 225 & 0 & 0 \\
\hline & $j=5$ & - & 60 & 0 & 60 & & 60 & 0 & 0 \\
\hline & $j=6$ & - & 40 & 0 & 40 & & 90 & 0 & 0 \\
\hline & total & - & 400 & 500 & 900 & & 700 & 0 & 250 \\
\hline
\end{tabular}


Table 3: Total profit of alternative scenarios

\begin{tabular}{|c|c|c|c|c|}
\hline $\begin{array}{c}\text { Scenario } \\
\#\end{array}$ & $\begin{array}{c}\text { Difference compared to } \\
\text { Scenario 1 }\end{array}$ & $\begin{array}{c}\text { Total profit of multi- } \\
\text { period model, } P_{M P M}\end{array}$ & $\begin{array}{c}\text { Total profit of single- } \\
\text { period model, } P_{S P M}\end{array}$ & $\begin{array}{c}\text { Percentage total profit } \\
\text { increase of multi- } \\
\text { period model (\%), } \Delta P\end{array}$ \\
\hline 1 & - & 6,740 & 6,695 & 0.67 \\
\hline 2 & salvpr $_{j, t}=5 \forall j, t$ & 9,045 & 9,045 & 0.00 \\
\hline 3 & fixedc $_{i, t}=1,000 \forall i, t$ & 740 & 615 & 20.33 \\
\hline 4 & $\begin{array}{c}D E M_{1}=900, D E M_{2}= \\
1200, D E M_{3}=1500\end{array}$ & 7,890 & 6,915 & 14.10 \\
\hline
\end{tabular}




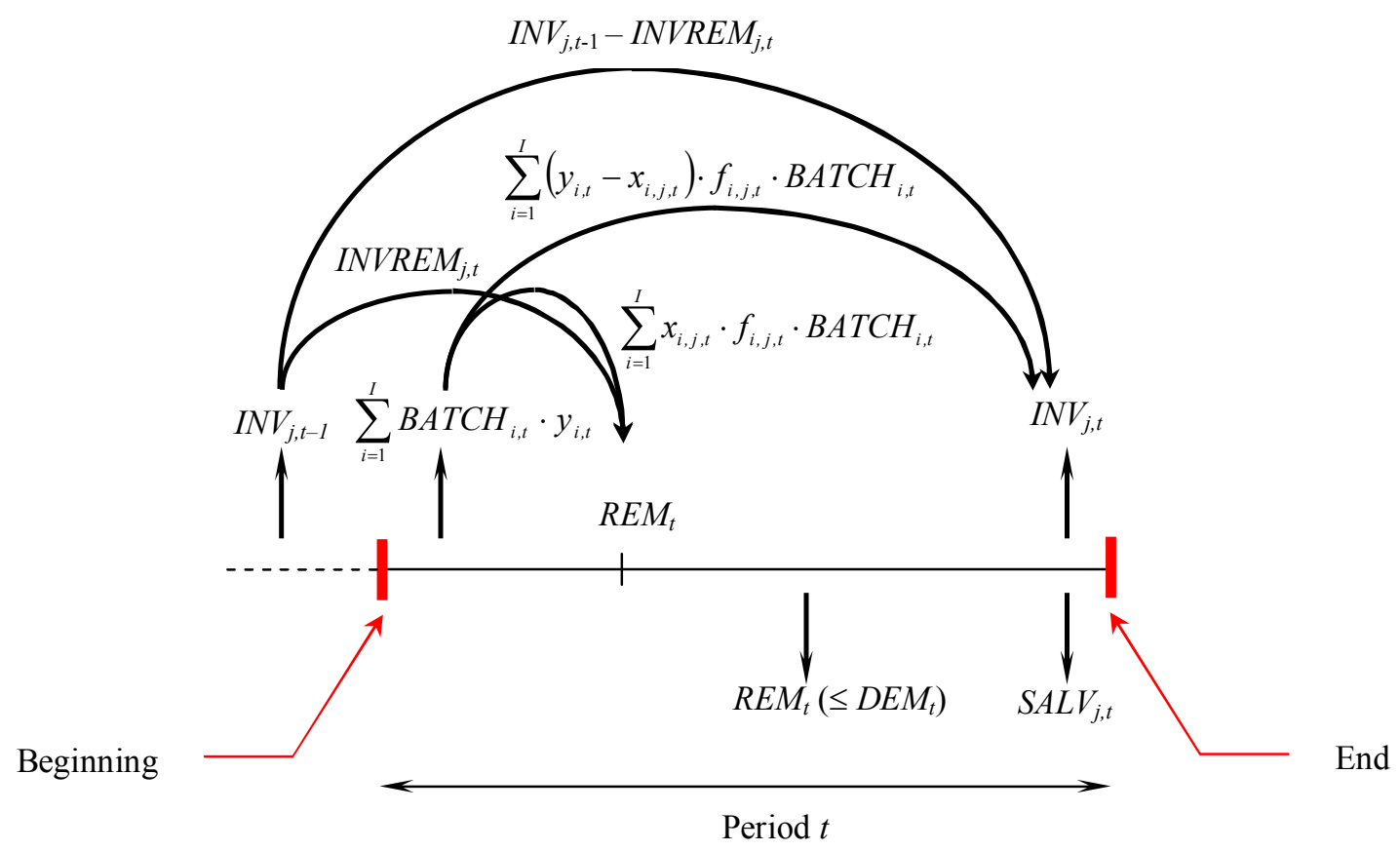

Figure 1: Interaction of quantities and events, at any period $t$ except for the first one, for every quality level $j$ 


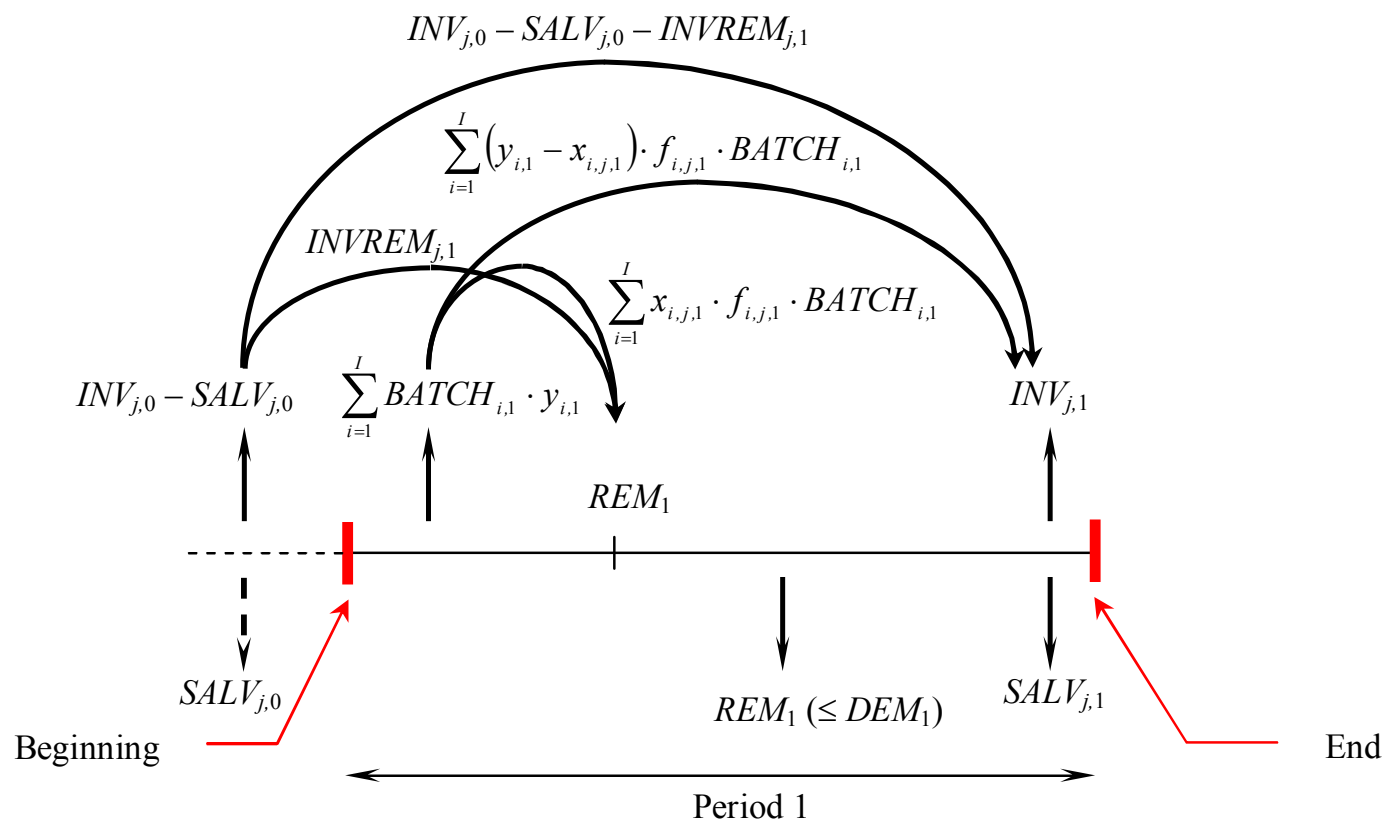

Figure 2: Interaction of quantities and events, at period $t=1$, for every quality level $j$ 


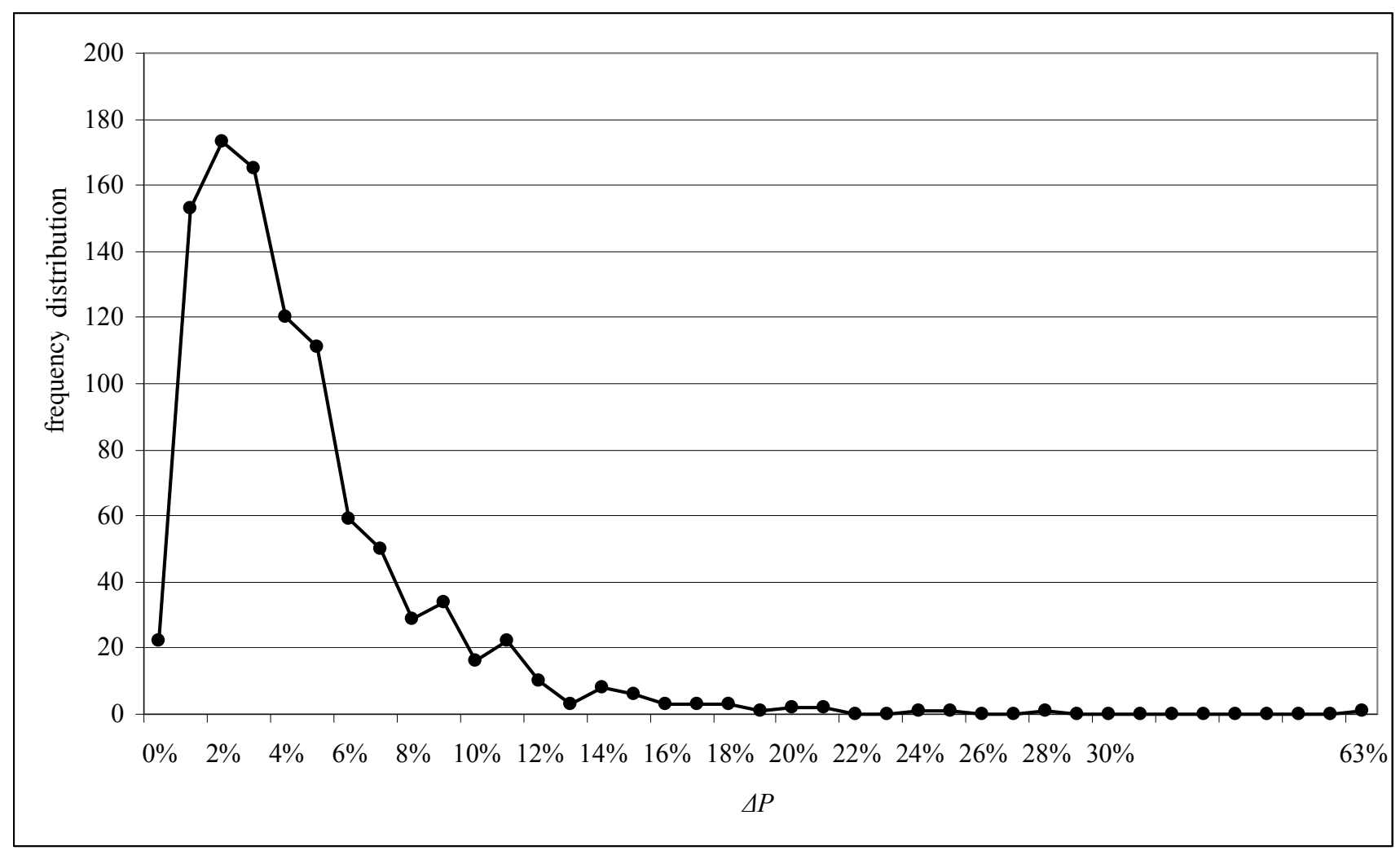

Figure 3: Frequency of $\Delta P$ 


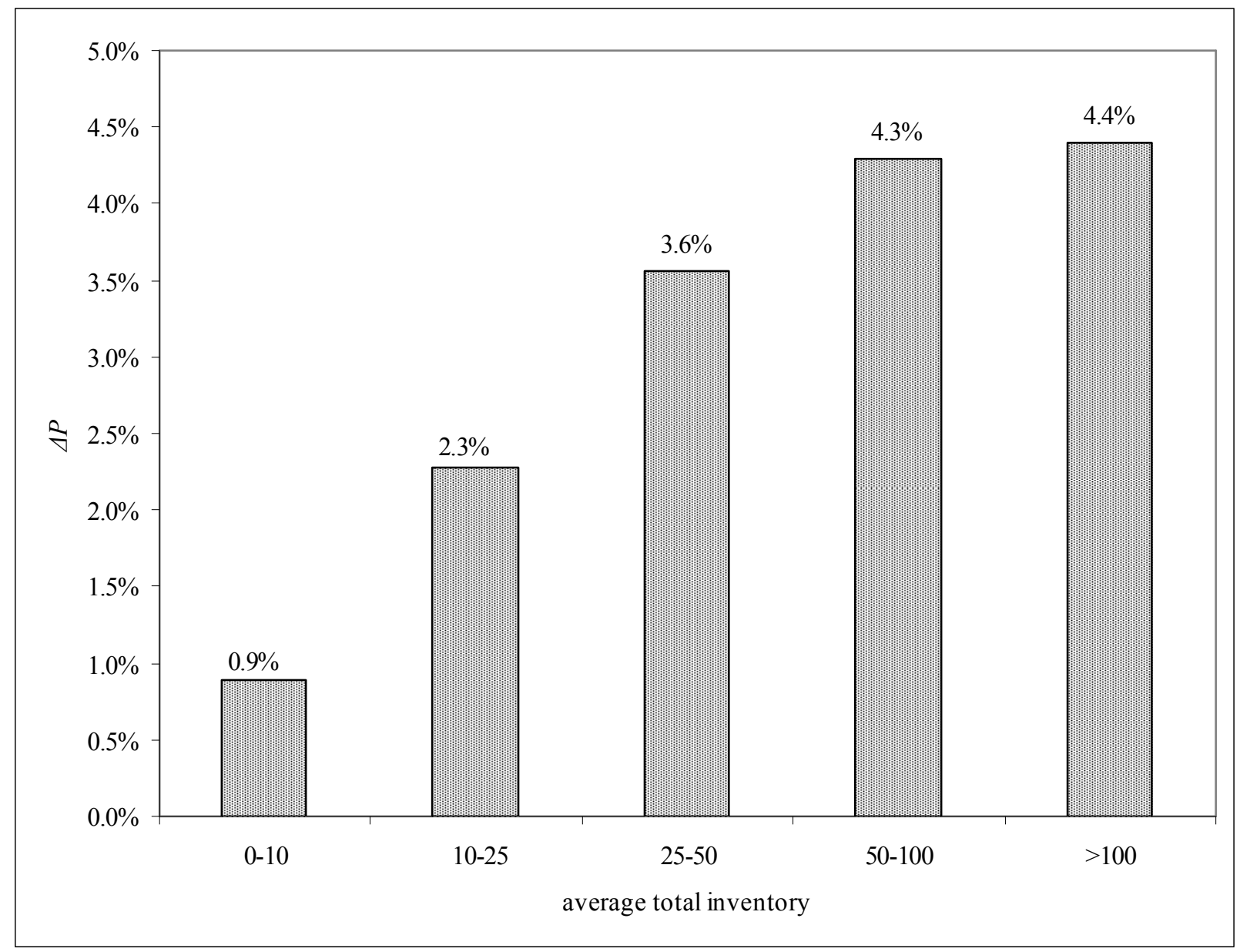

Figure 4: Percentage profit improvement with regard to average total inventory 


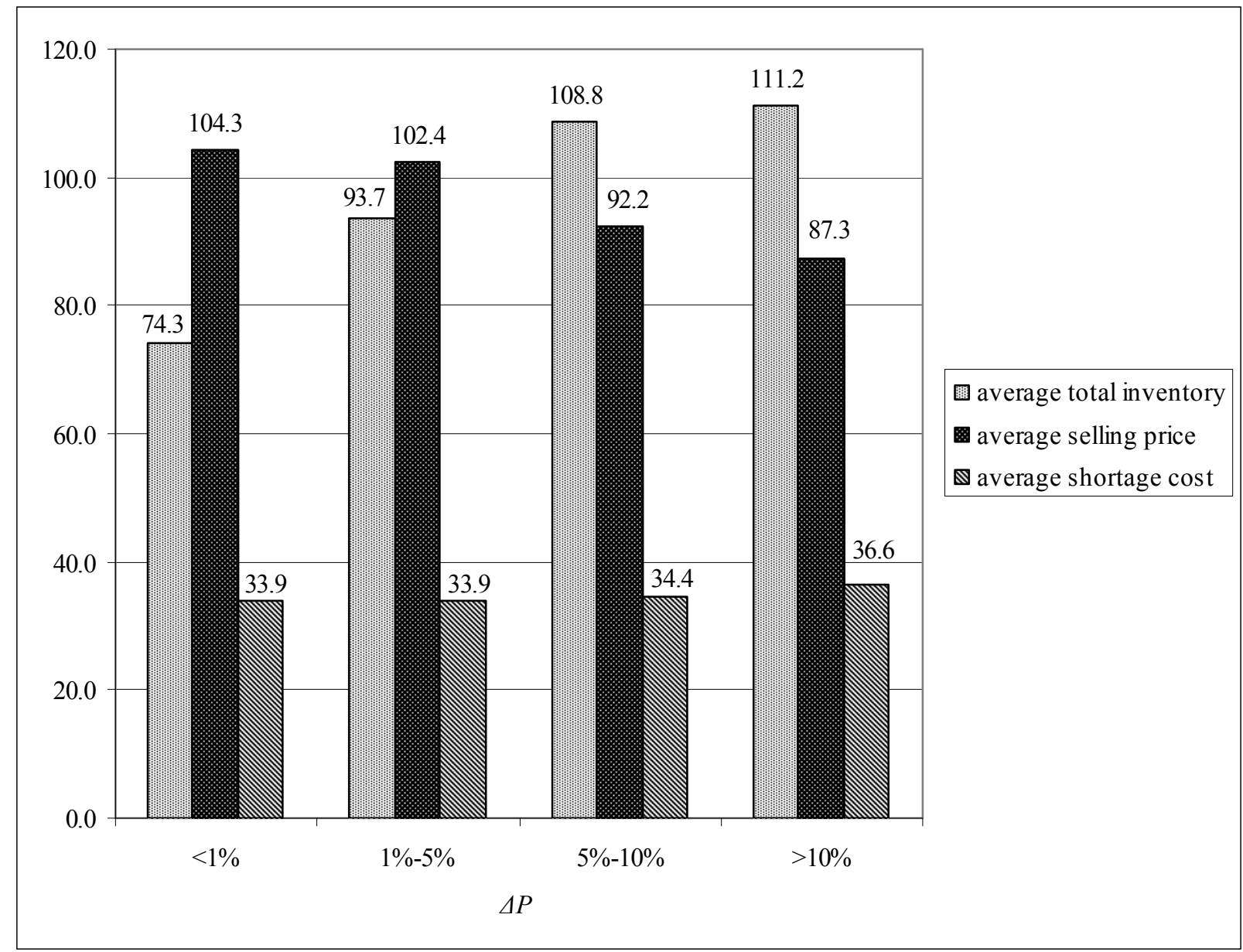

Figure 5: Average inventory, selling price and shortage cost with regard to percentage profit improvement 